\title{
ASPECTOS HIDRODINÂMICOS DA ENSEADA DA ARMAÇÃO DE ITAPOCOROY, SC.
}

\author{
C.A.F. SCHETTINI; J.L.B. de CARVALHO; E.C. TRUCCOLO \\ Laboratório de Oceanografia Física, CTTMar/UNIVALI, Cx.P. 360, Itajaí, SC \\ guto@cttmar.univali.br
}

\begin{abstract}
RESUMO
Este trabalho reúne informações disponíveis de variávies ambientais que permitem realizar uma avaliação das condições hidrodinâmicas da enseada da Armação de Itapocoroy. Dados de velocidade e direção de correntes, maré, vento, salinidade, temperatura, turbidez e a batimetria foram obtidos em diferentes ocasiões, porém em conjunto permitem elaborar um quadro preliminar da capacidade de suporte deste ambiente para manter a atividade de cultivo de moluscos marinhos. A taxa de renovação de água é da ordem de alguns dias, e a proximidade da desembocadura do estuário do Rio Itajaí-açu faz com que a pluma deste regularmente avance para o interior da enseada. A ação ocasional de ondas de tempestade de leste, juntamente com correntes devido ao vento e à maré, atuam na remoção de detritos gerados pelos cultivos.
\end{abstract}

Palavras-chave: hidrodinâmica, aquicultura, enseada da Armação do Itapocoroy.

\section{HYDRODINAMIC ASPECTS OF THE ARMAÇÃO DO ITAPOCOROY BIGHT, SC}

\begin{abstract}
This paper join available information of environmental variables which allow to assess the hydrodynamics of the Armação do Itapocoroy Bight. Data of current speed and direction, tide, wind, salinity, temperature, turbidity and the bathimetry were acquired at different occasions, although when they are evaluated together, they permit to build a preliminary picture about the holding capacity of this environment to maintain the mollusc aquaculture. The water renewal rate is of the order of some days, and the proximity of the Itajaí-açu River estuary mouth allow that the river plume enter in a regular bassis into the bight. The occasional storm waves from east, together with wind and tide currents, act in the remobilization of material generated by the mussel culture.
\end{abstract}

Keywords: hydrodynamics, acquaculture, Armação do Itapocoroy Bight.

INTRODUÇÃO

O litoral catarinense apresenta-se bastante rico em feições geomorfológicas, principalmente entre o Cabo de Santa Marta ao sul até a fronteira com o Paraná ao norte. Entre estas feições destacam-se dezenas de enseadas e baías, que em função de suas posições geográficas constituem locais pro- pícios para o desenvolvimento de atividades de maricultura.

A enseada da Armação de Itapocoroy (Figura 1) vêm se destacando como um dos principais sítios de cultivo de moluscos marinhos no Estado de Santa Catarina, e apresenta indícios de que irá crescer consideravelmente ainda mais nos próximos anos. No entanto, o crescimento de qualquer atividade 
sobre a região costeira necessita de planejamento prévio para que esta atividade apresente sustentabilidade ao longo do tempo. No caso da maricultura, o conhecimento detalhado das variáveis ambientais é de fundamental importância, sendo que as condições hidrodinâmicas se destacam entre estas.

O objetivo deste trabalho é reunir informações referentes à hidrodinâmica da Enseada da Armação de Itapocoroy a partir da dados coletados em diversas ocasiões, e fornecer uma análise da circulação e renovação de águas desta enseada.

\section{Condições Ambientais da Enseada da Ar- mação de Itapocoroy}

\section{Fisiografia}

A Enseada da Armação do Itapocoroy (Figura 1) apresenta profundidade máxima de 15 metros, e média de $8 \mathrm{~m}$. A enseada é cercada por morros de até 250 metros de altitude. A sua orientação geográfica SE-NW e o posicionamento dos morros que a contornam tornam a enseada abrigada de ondas e ventos provenientes do quadrante sul, constituindo-se de um abrigo natural para embarcações. Esta fisiografia favorece a atividade de cultivo de moluscos devido ao fato de que as forçantes hidrodinâmicas são atenuadas localmente.

A área aproximada da enseada é de $6,7 \mathrm{~km}^{2}$, considerando seu limite com o mar aberto a linha que une a Ponta do Vigia até a Lage do Largo (Figura 1), distantes 4,2 km entre si. Um indicativo do grau de abertura da enseada pode ser dado pela razão entre o seu limite aberto com o seu perímetro úmido (7,2 km medido na escala 1:30.000), apresentando um valor de 0,6. Valores próximos da unidade representam linhas de praia, enquanto que valores próximos de zero representam lagoas costeiras.

A hipsometria da enseada (Figura 2) é outra característica fisiográfica que indica uma grande interação com o mar aberto. A forma côncava da curva caracteriza a ausência de planos intermareais, e praticamente não há variação da área submersa da enseada ao longo de ciclos de maré.

\section{Regime de Ventos}

O clima de ventos regional é controlado pelo sistema de alta pressão do Atlântico sul, o qual gera o padrão predominante de ventos oriundos de nordeste durante a maior parte do tempo. Periodicamente este padrão é alterado pelo avanço de sistemas polares frontais, os quais mudam o sentido do vento por poucos dias para ventos provenientes do quadrante sul. Os sistemas polares são mais intensos e freqüentes durante o inverno, porém mesmo durante este período os ventos de nordeste são predominantes (Nimer, 1989).

A estação anemométrica mais próxima da enseada da Armação de Itapocoroy está localizada no aeroporto de Navegantes. Os dados de vento disponíveis para esta estação compreendem o período de junho a dezembro de 1996, na freqüência de aquisição de dados de 6 horas. A distribuição de densidade vetorial dos dados de vento é mostrada na Figura 3. Podemos observar claramente um padrão de ventos fracos durante a maior parte do tempo, provenientes de qualquer quadrante porém com maior freqüência de ventos provenientes de oeste, nordeste e sudoeste. Ventos mais intensos são observados em nuvens distintas de densidade em nordeste e sudeste, possivelmente associados com eventos mais intensos de passagen de sistemas frontais.

A densidade espectral das series temporais dos dados de ventos decompostos para as componentes norte-sul e leste-oeste são apresentadas na Figura 4. A densidade espectral da componente norte-sul mostrou um padrão similar a outras análises com dados de outras estações anemométricas, com picos bem definidos para os períodos entre 6 e 7 dias. Pode-se distinguir também um pico menos saliente para um período de 24 horas. 
Na distribuição espectral da componente leste-oeste, o pico mais saliente situa-se no período de 24 horas, com 3 'mais energia do que os demais picos. Em ambos os gráficos a primeira seta indica o pico de 24 horas, sendo associado possivelmente com o efeito de brisa marinha no vale do Rio Itajaí-açu, e a segunda indica o pico de 6 a 7 dias associado com os eventos de passagens de frentes frias. Isto indica que o fenômeno de brisa marinha desempenha um papel que deve ser considerado nos estudos da oceanografia costeira local.

\section{Regime de Marés}

A maré astronômica local apresenta uma altura média de 0,8 $\mathrm{m}$, com máximas de $1,2 \mathrm{~m}$ durante os períodos de sizígia, e mínimas de $0,3 \mathrm{~m}$ durante os períodos de quadratura. $O$ regime de maré é semi-diurno com desigualdade de altura para preamares

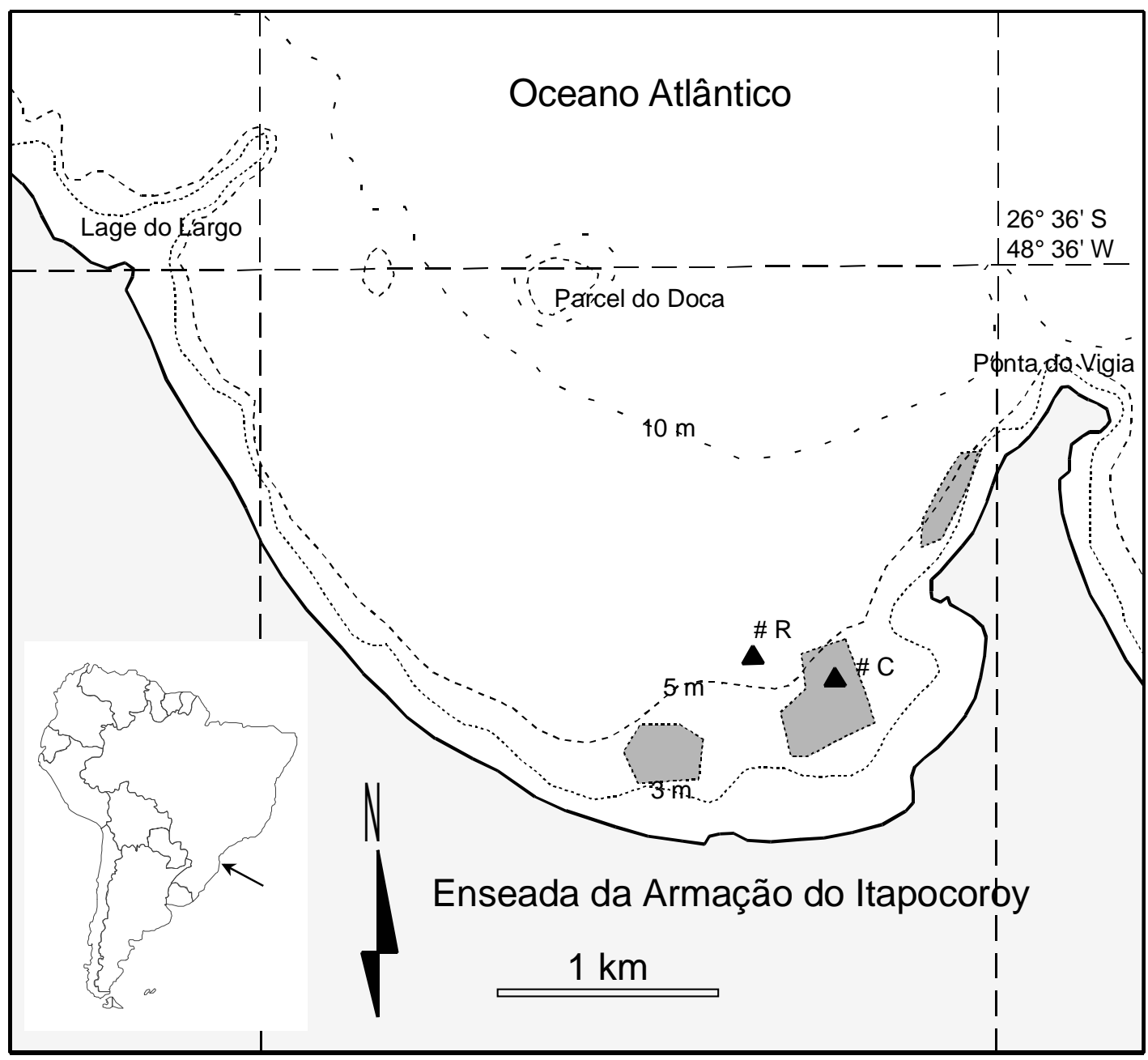

Figura 1: A enseada da Armação de Itapocoroy, SC. 
e baixamares consecutivas. O número de forma, dada pela soma dos principais constituintes harmônicos diurnos sobre os principais constituintes semi-diurnos, $\left[\left(\mathrm{O}_{1}+\mathrm{K}_{1}\right) /\left(\mathrm{M}_{2}+\mathrm{S}_{2}\right)\right]$ (Pugh, 1987), é 0,4 (Schettini et al., 1996).

Dados obtidos na estação maregráfica do Centro de Ciências Tecnológicas da Terra e do Mar (CTTMar-UNIVALI) indicam que ocorrem também oscilações do nível do mar em freqüências sub-horárias. Tais freqüências são creditadas ao período de oscilação natural de sistemas aquáticos restritos e semirestritos, também denominado de seiche. As observações maregráficas indicam que esta oscilação apresenta período de aproximadamente 30 minutos com altura de até $0,2 \mathrm{~m}$.

Oscilações do nível do mar devido a fenômenos atmosféricos são bastante importantes regionalmente. A ocorrência de ventos provenientes do sul durante a passagem de sistemas frontais ocasionam 0 empilhamento de águas junto a costa pelo transporte de Ekman. Sobre elevações do nível do mar da ordem de $1 \mathrm{~m}$ podem ocorrer em função da intensidade dos ventos (Truccolo, 1998).

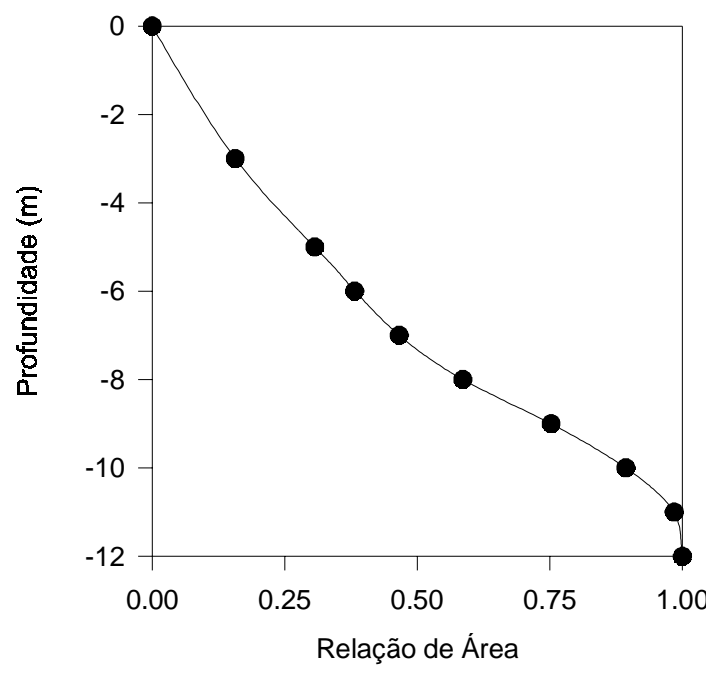

Figura 2: Curva hipsométrica da enseada da Armação de Itapocoroy, SC.

\section{Regime de Ondas}

O regime de ondas para a região sul do Brasil ainda não é suficientemente conhecido, porém alguns padrões podem ser definidos. Em resposta ao regime de ventos, ondas provenientes de nordeste predominam durante a maior parte do tempo com alturas modestas e períodos inferiores a $8 \mathrm{~s}$. Ondas provenientes do sul originadas em tempestades de altas latitudes, por sua vez, apresentam-se com alturas maiores e com períodos de até $16 \mathrm{~s}$.

A posição da enseada a torna abrigada do ataque direto das ondulações mais energéticas provenientes do sul. As ondas sofrem os processos de refração e difração que reduzem significativamente sua altura e energia na enseada. Entretando, a região recebe esporadicamente ondulações provenientes de leste, popularmente denominadas de lestadas. Estas ondulações incidem mais diretamente com pouca perda de energia ao

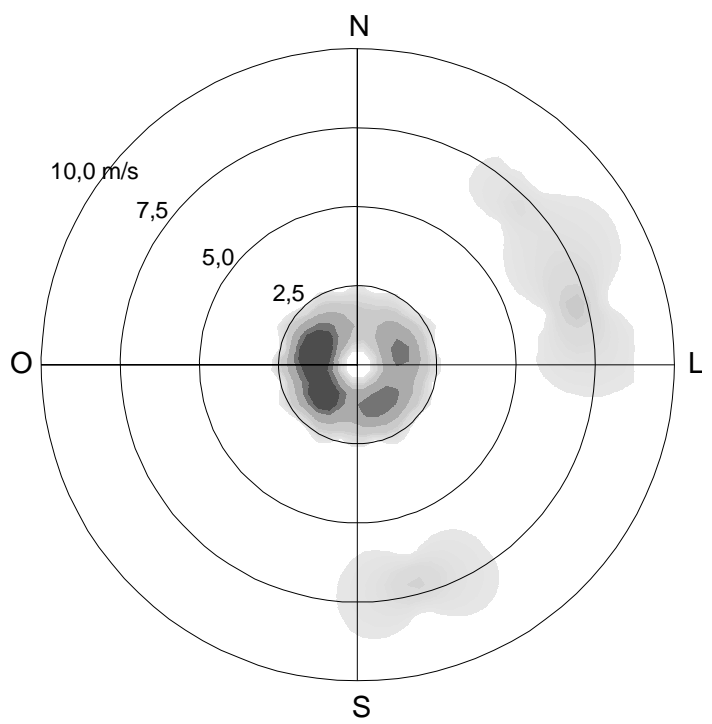

Figura 3: Distribuição polar de densidade de vetores de vento, para o período de junho a dezembro de 1996. 
entrarem na enseada. Este é o sistema mais energético que atua na dinâmica sedimentar da enseada. A ocorrência destas ondulações apresentam um importante papel na remobilização de sedimentos finos depositados nos períodos de baixa energia.

\section{Regime de Correntes}

A hidrodinâmica da enseada da Armação de Itapocoroy é bastante complexa. As correntes observadas localmente são o resultado do somatório de diversas forçantes oceanográficas e meteorológicas em termos locais e distantes. As principais forçantes locais são as correntes geradas pelo vento e pela maré.

Dados de velocidade e direção de corrente obtidos com o fundeio de dois correntógrafos SD6000 por um período de 7 dias em outubro de 1994, indicam que as correntes na região apresentam valores usualmente inferiores à $0,1 \mathrm{~m} \cdot \mathrm{s}^{-1}$, obedecendo mais

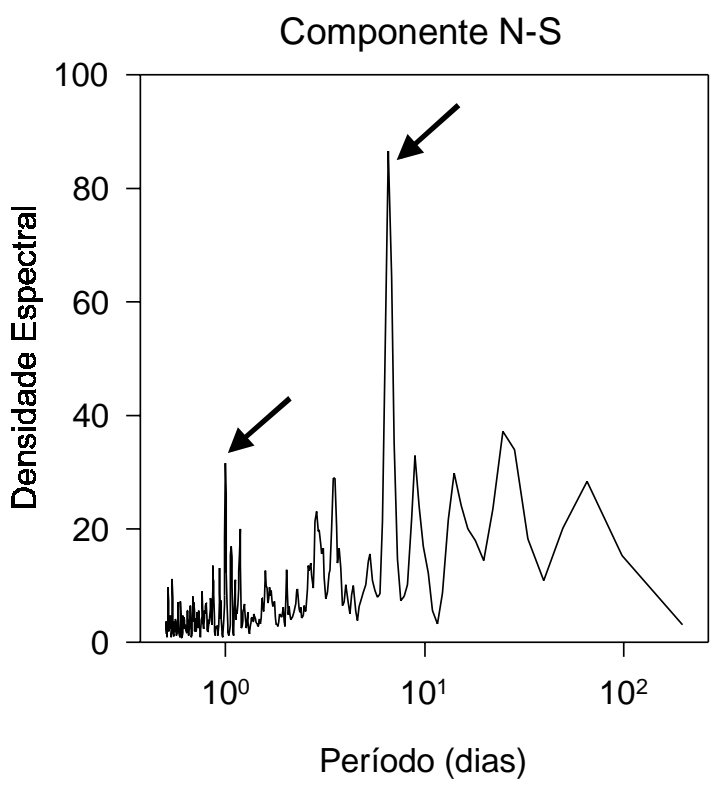

diretamente o regime de ventos do que a oscilação causada pelas marés.

A distribuição polar de densidade de vetores para dois pontos onde foram coletadas informações de velocidade e direção de correntes são muito semelhantes (Figura 5). De maneira geral, acompanham a orientação da linha de costa, com direção nordeste-sudoeste, com a deflexão da corrente ocorrendo para o quadrante de sudeste, sendo que as correntes predominantes durante este período foram para nordeste.

\section{Salinidade e Temperatura}

No litoral centro-norte de Santa Catarina ocorrem três tipos de massas de água distintos. Próximo à região costeira ocorre a Água Costeira (AC) com baixas salinidades $(<34 \%$ ) e a temperatura variando sazonalmente entre 19 e $28{ }^{\circ} \mathrm{C}$ entre inverno e verão, respectivamente. A extensão da ocorrência da $A C$, bem como a sua

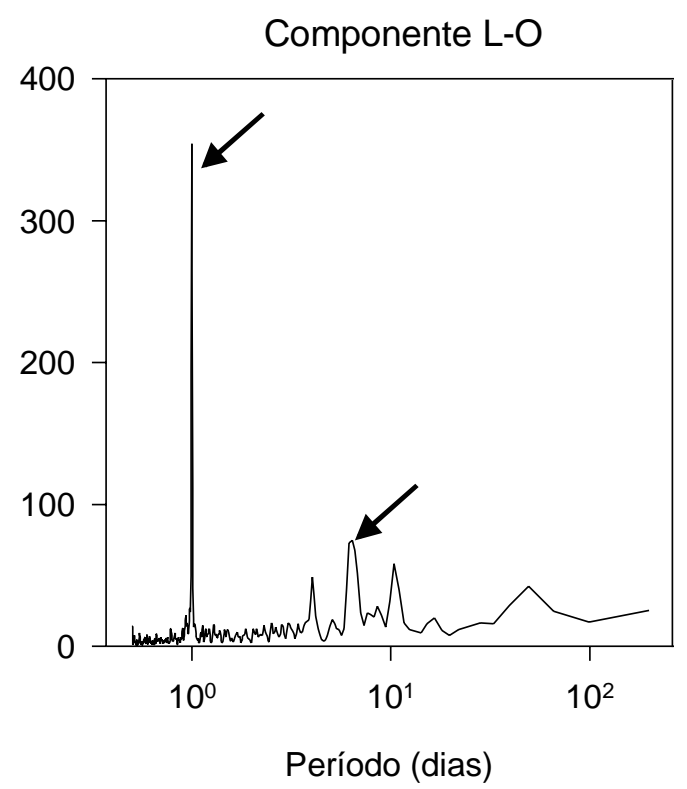

Figura 4: Distribuição de densidade espectral dos componentes norte-sul e leste-oeste dos dados de vento. As setas indicam os períodos de 24 horas, e 6 a 7 dias. 
salinidade, dependem do aporte continental, podendo alcançar dezenas de quilômetros em direção ao oceano durante períodos de máximos pluviométricos. A Água de Plataforma (AP) ocorre mais afastada da costa, apresentado salinidade mais elevada (> $35 \%$ ) e temperatura mais elevada, e a Água Central do Atlântico Sul (ACAS) é observada somente em profundidade e durante os meses de primavera e verão, sendo caracterizada por elevada salinidade e temperatura inferiore à 18 ${ }^{\circ} \mathrm{C}$ (Carvalho et al., 1998).

A AC é a massa de água predominante que ocupa a enseada da Armação de Itapocoroy. A sua formação local é determinada principalmente pela contribuição fluvial do Rio Itajaí-açu, cuja desembocadura está localizada a 20 quilômetros para sul. Entretanto, antes de formar a AC local, a descarga do Rio Itajaí-açu forma uma pluma fluvial que consiste de outra massa de água importante localmente, caracterizada pela salinidade extremamente baixa e elevada carga de sedimento em suspensão.

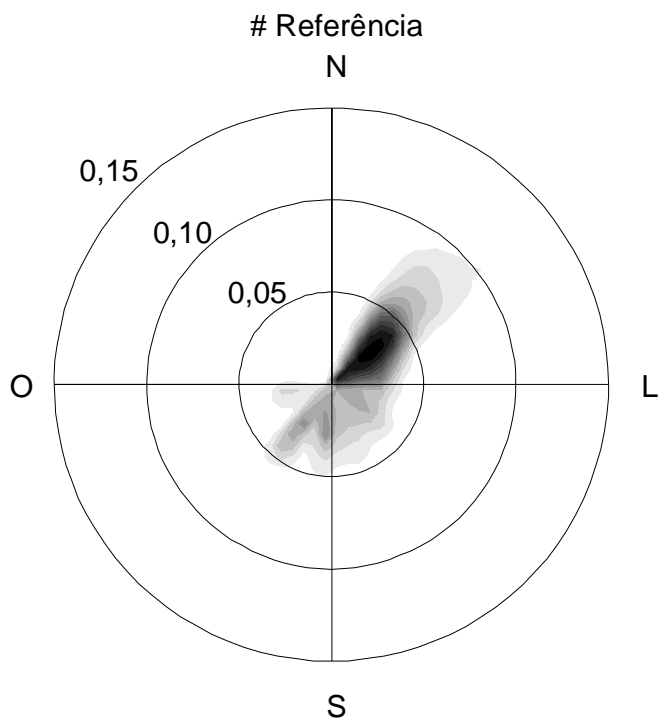

A pluma fluvial formada a partir da barra do Rio Itajaí-açu é uma feição de mesoescala costeira de caráter efêmero, ocorrendo em função das condições hidrológicas na bacia de drenagem do rio. A dispersão da pluma ocorre predominantemente para nordeste, porém diferentes padrões podem ser observados em função da variação dos forçantes meteorológicos e oceanográficos (Schettini et al., 1998). Uma característica da pluma fluvial é a formação de frontes bem definidas separando diferentes massas de água.

A Figura 6 mostra séries temporais horárias da variação do nível da água, salinidade e temperatura, para o período de 10 a 17 de março de 1995. Podemos verificar que durante os primeiros dias dos registros a salinidade apresentou-se bastante variável, com oscilações abruptas ocorrendo em intervalos de tempo inferiores à 1 hora. O mesmo não foi observado em relação à temperatura. Tais oscilações provavelmente estão associadas com as corrente de maré com a presença de uma fronteira entre massas de AC com diferentes idades de formação. Esta fronteira

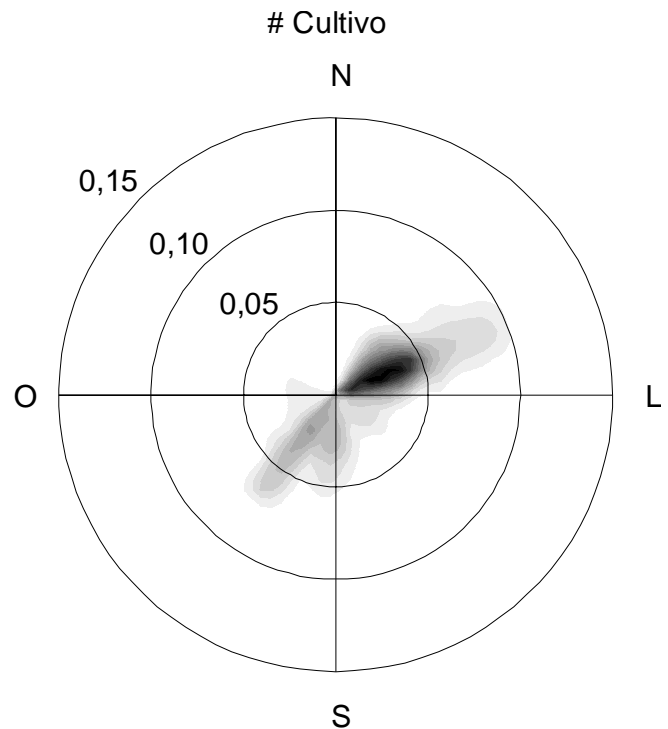

Figura 5: Distribuição polar de densidade de vetores de corrente, para o período de 24 a 31 de outubro de 1994. 
NOTAS TÉC. FACIMAR, 3: 99-109, 1999.
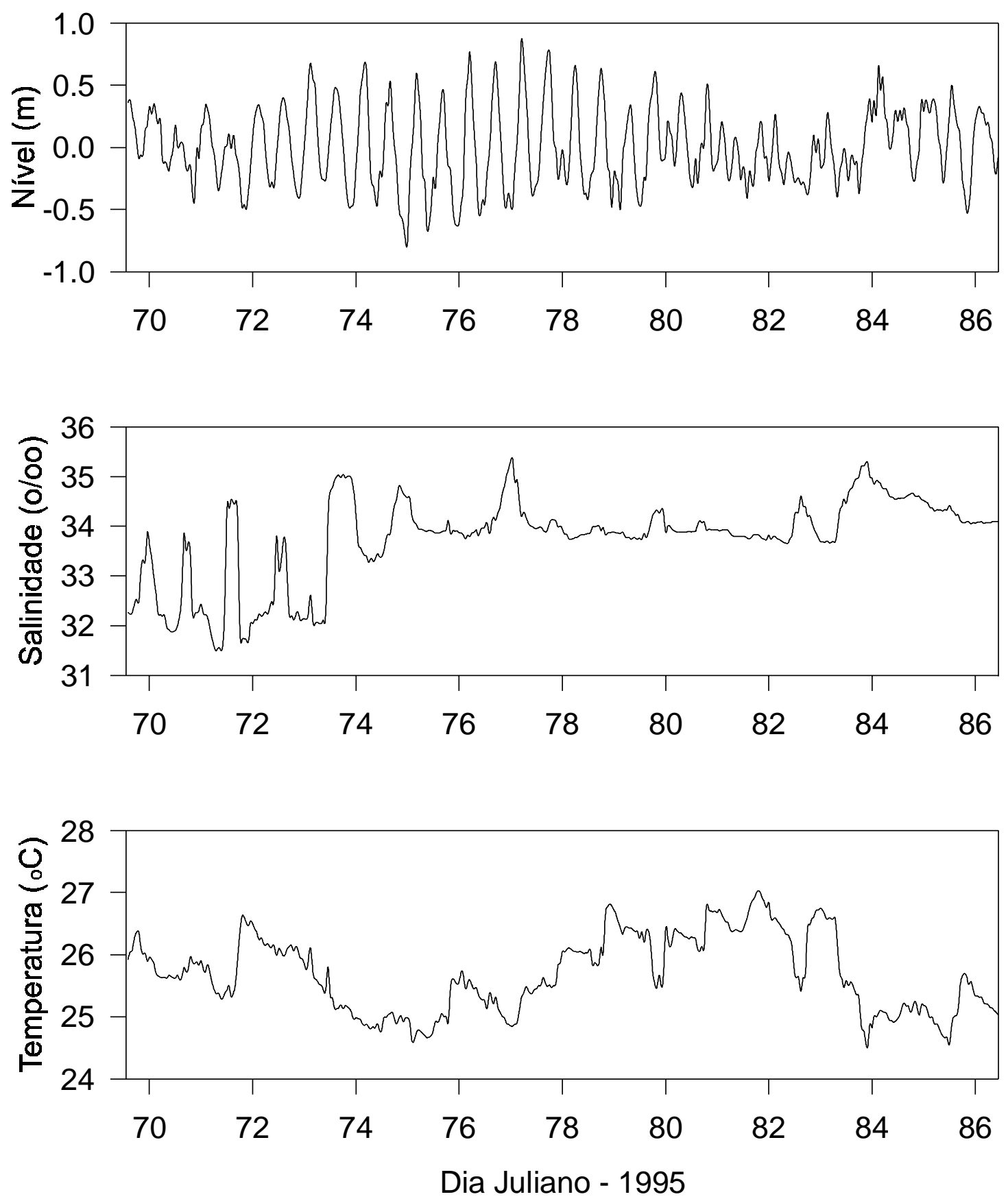

Figura 6: Distribuição temporal dos dados de nível da água, salinidade e temperatura, para o período de 10 a 27 de março de 1995. 
é evidenciada no diagrama TS (Figura 7) onde distingue-se duas nuvens de pontos bem definidas.

As distribuições de densidade espectral (DDE) referentes às séries temporais do nível do mar, salinidade e temperatura são mostrados na Figura 8. A DDE do nível do mar mostra claramente a concentração de energia nos picos de 6, 8, 12 e 24 horas, referentes aos principais espécies harmônicas da maré, sendo a maior concentração em períodos em torno de 12 horas. A densidade espectral em torno de 24 horas não apresenta um pico bem definido como as demais, indicando a presença de fenômeno cíclico influenciando o nível do mar. A DDE da salinidade mostra um pico referente ao período de 1 dia, porém a energia está dispersa em períodos superiores a 7 dias, o que também é observado para a distribuição de densidade espectral da temperatura. O pico difuso em torno de 24 horas da salinidade e do nível do mar podem estar associados com o efeito da brisa marinha, evidenciada no espectro de densidade da componente leste-oeste do vento (Figura 4).

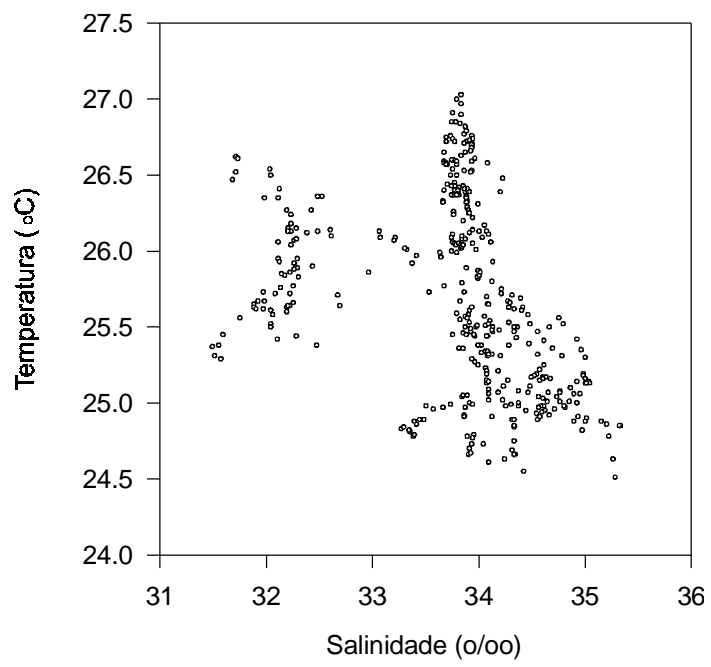

Figura 7: Diagrama T-S para o período de 10 a 27 de março de 1995.

\section{Turbidez}

A turbidez observada na Enseada da Armação de Itapocoroy é provenientes de duas fontes principais: (1) a pluma fluvial do Rio Itajaí-açu, e (2) a ressuspensão de sedimentos de fundo deposidados durante períodos de baixa energia ou devido ao processo de biosedimentação decorrente da atividade de cultivo de moluscos marinhos (Schettini et al., 1997).

A contribuição de turbidez da pluma fluvial é dependente das condições oceanográ-

(a)

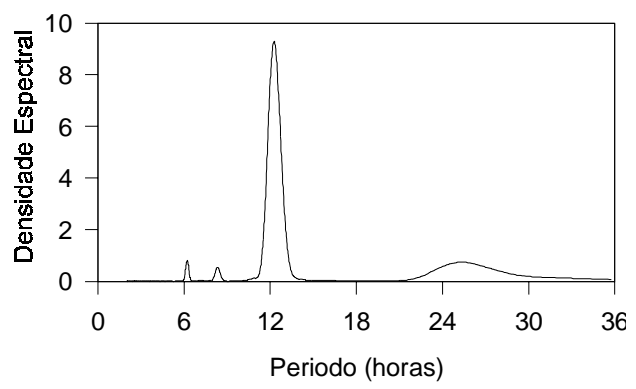

(b)

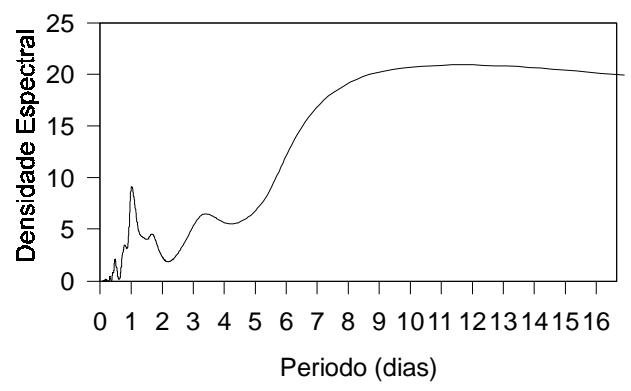

(c)

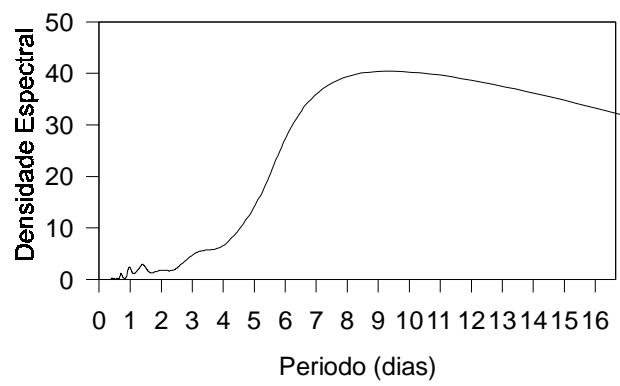

Figura 8: Distribuição de densidade espectral dos dados de nível da água, salinidade e temperatura. 
ficas e meteorológicas atuantes na dispersão da mesma. Porém, como a direção predominante do espalhamento da pluma é para nordeste, a região da enseada recebe continuamente águas costeiras recentemente formadas com uma grande contribuição de constituintes da pluma fluvial, e.g., turbidez, nutrientes, etc.

Durante períodos de baixa energia, e.g., marés de quadratura, ausência de ondas, etc., e devido a contínua filtração dos moluscos, a enseada apresenta condições para sedimentação de sedimentos finos. Porém, devido a sua condição aberta, condições de alta energia ocorrem periodicamente fornecendo condições para ressuspender e transportar os sedimentos finos previamente depositados.

A Figura 9 mostra séries temporais de 34 horas de dados de nível do mar na Estação Maregráfica da Penha, e vetores de corrente e turbidez coletados na \# C (Figura 1). A turbidez mostra claramente uma relação com o nível do mar, porém nenhuma relação óbvia existe com os vetores de corrente. Provavelmente com medições mais acuradas da direção e intensidade de correntes seja possível estabelecer padrões associados entre correntes de marés e a turbidez observada na enseada.

\section{Tempo de Renovação de Águas}

O tempo de renovação das águas de um sistema costeiro semi-restrito representa o tempo necessário para que $100 \%$ da água do sistema seja trocada por outra. Entretanto, o tempo para renovação tende ao infinito quando a renovação se aproxima de $100 \%$, sendo mais prático adotar o conceito de meiavida como o tempo nescessário para renovar apenas $50 \%$ do volume (Knoppers, et al., 1991).

Considerando que a renovação do volume $V$ ao longo do tempo $t$ se dê através de uma razão $k$ constante,

$$
\frac{d V}{d t}=-k . V
$$

(Pritchard, 1961), esta pode ser integrada a partir de um instante inicial quando temos um volume $V_{0}$ até um lapso de tempo, $T_{50 \%}$, quando o volume permanecerá o mesmo mas apenas metade será constituído pela parcela de água inicial, ou $V_{\text {novo }} / V_{50 \%}=0,5$. A integração fornecerá que

$$
T_{50 \%}=\frac{0,69}{k}
$$

(Knoppers et al., 1991). A razão de renovação $k$ depende de diversos fatores que influenciam o balanço hidrológico de determinado sistema. Para ambientes semi-restritos como enseadas, o fator preponderante são as trocas causadas pela oscilação da maré.

Uma maneira prática de expressar a renovação diária causada pelas marés semidiurnas é através do prisma de maré

$$
Q_{M}=A \cdot \Delta m \cdot \frac{24,00}{12,42}
$$

onde $A$ é a área da enseada e $D m$ é a altura média da maré. A razão $k$ representa a fração de água trocada por dia, determinada por

$$
k=\frac{Q_{M}}{V}
$$

A taxa de renovação diária causada pelo prisma de maré para a enseada da Armação de Itapocoroy, considerando a altura média de maré de $0,8 \mathrm{~m}$, é » $10,4 \cdot 10^{6} \mathrm{~m}^{3}$, cuja relação com o volume da enseada, 53,6

$10^{6} \mathrm{~m}^{3}$, fornece um $\mathrm{k}=0,19$, e um $\mathrm{T}_{50 \%}=3,6$ dias. Obviamente a água que periodicamente é trocada com o mar adjacente não é água 
SCHETTINI et al::Hidrodinâmica da Enseada da Armação do Itapocoroy.
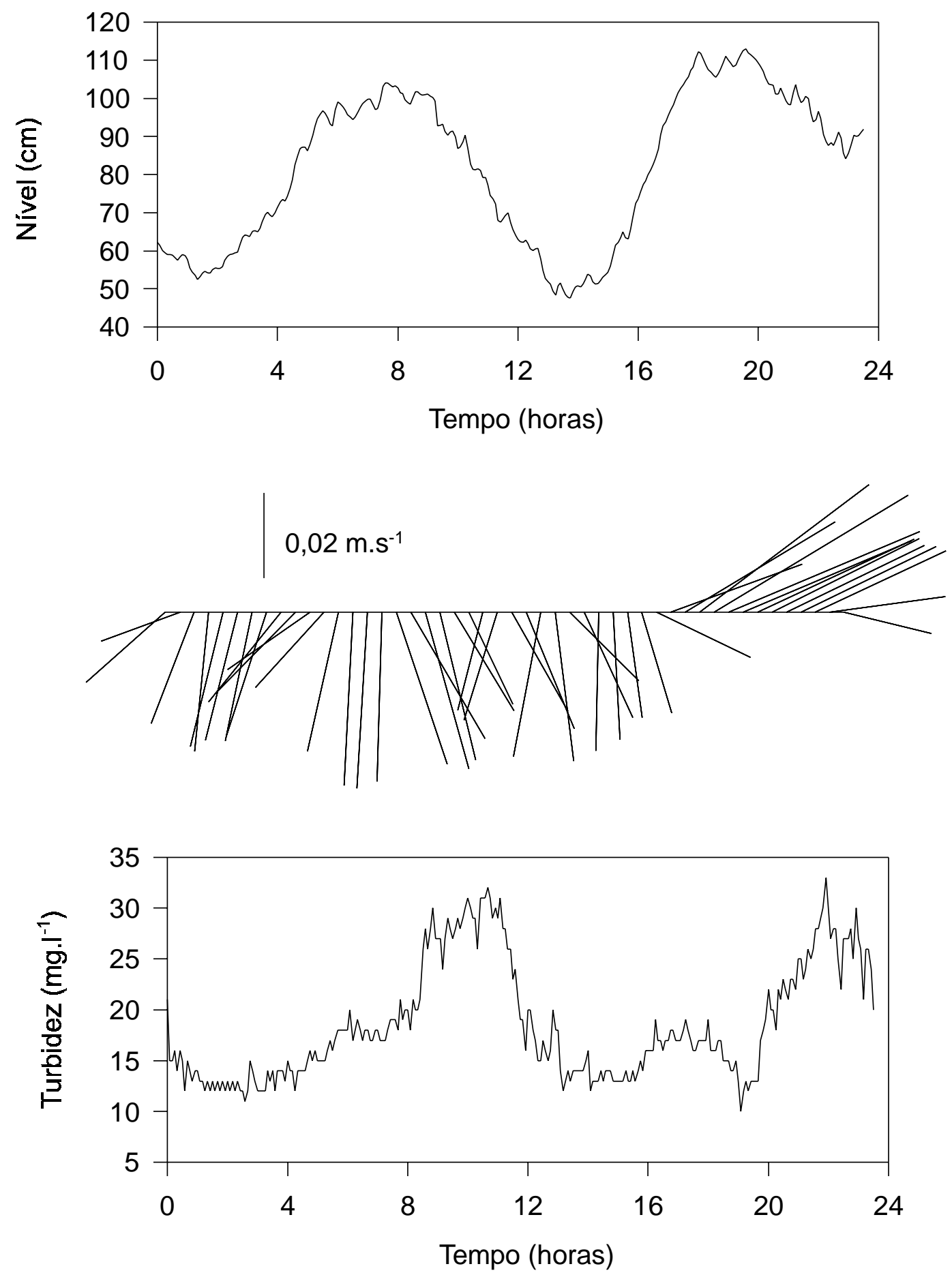

Figura 9: Dados de maré, vetores de corrente e turbidez, para o período de 25 e 26 de agosto de 1996. 
'nova', mas provavelmente uma parcela que saiu na vazante entrará novamente na enchente seguinte. Contudo o valor de $\mathrm{T}_{50 \%}$ forncece um indício de que a água da enseada é renovada em uma questão de dias.

\section{CONSIDERAÇÕES FINAIS}

A enseada da Armação de Itapocoroy é uma de muitas enseadas semi-abrigadas do litoral catarinense onde a atividade de cultivo de moluscos vêm crescendo significativamente. $O$ sucesso da atividade de cultivo depende grandemente da capacidade de suporte do ambiente, e a hidrodinâmica é um dos elementos chave na determinação desta capacidade.

A partir da análise de dados oceanográficos coletados em diversas oportunidades, é possível estabelecer que a Enseada da Armação do Itapocoroy apresentam condições favoráveis para receber e desenvolver a atividade de cultivo de moluscos marinhos. A contribuição da pluma fluvial do Rio Itajaí-açu provavelmente mantém os níveis de produção primária costeira regional elevados, e o curto período de tempo para renovação da água da enseada possibilita uma contínua entrada de alimento para os moluscos.

A recorrente ação de ondas de tempestades provenientes de leste, as lestadas, embora causem prejuízos às estruturas de cultivo, desempenham um papel importante na remobilização do material acumulado no fundo. A ação das ondas atua na resuspensão deste material enquanto que as correntes geradas pelo vento e pelas marés atuam no transporte.

\section{REFERÊNCIAS BIBLIOGRÁFICAS}

Carvalho, J.L.B.; Schettini C.A.F.; Ribas, T.M. 1998. Estrutura termohalina do litoral centro norte catarinense. Notas Técnicas da Facimar. 2:181-197.
Knoppers, B.; Kjerfve, B.; Carmouze, J.P. 1991. Trohpic state and water turn-over time in six choked coastal lagoons in Brazil. Biogeochemistry. 14:149-166.

Nimer, E. 1989. Climatologia do Brasil. IBGE, Rio de Janeiro. 421pp.

Pritchard, D. 1961. Disposal of radioactive wastes in the ocean. Health Physics. 6:103-109.

Pugh, D.T. 1987. Tides, surges and mean sea level. New York, John Wiley and Sons, $472 p$.

Schettini, C.A.F.; Carvalho, J.L.B.; Jabor, P. 1996. Comparative hydrology and suspended matter distribution of four estuaries in Santa Catarina Satate Southern Brazil. Workshop on Comparative Studies of Temperate Coast Estuaries, Bahia Blanca, Proceedings... IADO, p.29-32.

Schettini, C.A.F.; Kuroshima, K.N.; Pereira Fo., J.; Rörig, L.R.; Resgalla Jr., C. 1998. Oceanographic and ecological aspects of the Itajaí-açu river plume during a high disharge period. Anais da Academia Brasileira de Ciências. 70:325-334.

Schettini, C.A.F.; Resgalla Jr., C.; Kuroshima, K.N. 1997. Avaliação preliminar da taxa de sedimentação na região de cultivo de molucos (Perna perna) na Enseada da Armação-SC. Notas Técnicas da Facimar. $1: 1-7$.

Truccolo, E.C. 1998. Maré meteorológica e forçantes atmosféricas locais em São Francisco do Sul, SC. Dissertação de Mestrado, UFSC, 100p. 